\title{
Vigilancia epidemiológica de Acinetobacter baumannii multirresistente a nivel hospitalario
}

\author{
Epidemiological surveillance of multidrug-resistant Acinetobacter baumannii at hospital level \\ Vigilância epidemiológica do Acinetobacter baumannii multirresistente em nível hospitalar
}

\section{Rosa Carolina Encalada Álvarez}

caroencalada93@hotmail.com

https://orcid.org/0000-0001-5284-8933

\author{
Sandra Denisse Arteaga Sarmiento \\ sarteagas@ucacue.edu.ec \\ https://orcid.org/0000-0002-9734-9553
}

\section{Programa de Maestría en Diagnóstico de Laboratorio Clínico y Molecular Universidad Católica de Cuenca, Ecuador}

Recibido 25 de mayo 2021 / Arbitrado y aceptado 22 de junio 2021 / Publicado 13 de diciembre 2021

\section{RESUMEN}

La Acinetobacter baumannii se considera como un agente microbiano de gran importancia clínica debido a la resistencia que ha adquirido a los antimicrobianos, esto trae como consecuencias complicaciones al referir una terapia antibiótica, prolongando la estancia en la hospitalización de los pacientes infectados con esta bacteria, causando un alto grado de mortalidad por su elevada capacidad de proliferación en las diferentes áreas hospitalarias. Objetivo. Describir la epidemiología de los brotes causados por Acinetobacter baumannii en Latinoamérica, así como también los mecanismos de Resistencia de este patógeno causando inconvenientes al momento de emplear los diferentes tratamientos terapéuticos. Material y métodos. Es una revisión sistemática bajo la declaración PRISMA de las investigaciones relacionadas al tema. Para la búsqueda de información se emplearon fuentes de datos provenientes de: Scielo, Redalyc, Google académico, se encontraron 43 artículos de los cuales solo 25 fueron válidos para la investigación. Resultados. La resistencia que presenta la Acinetobacter baumannii a los antibióticos se incrementó con el pasar de los años. Este incremento de la resistencia se debe a diversos factores entre los cuales se destacan el desarrollo de ß-lactamasas dirigidas contra los betalactámicos, ya sea de amplio espectro o carbapenemasas; variaciones en las proteínas que forman parte de la membrana externa bacteriana, en las bombas de expulsión, perdida de porinas, modificaciones del lugar (blanco o diana) de acción de los antibióticos y variaciones en la expresión de proteínas fijadoras de penicilina. Esta variabilidad depende en parte de la capacidad de la bacteria para adquirir genes de resistencia, a menudo a través de una transferencia horizontal de genes Conclusiones. La Acinetobacter baumannii se caracteriza por tener múltiples mecanismos de resistencia a antibióticos, lo que ha aumentado las consecuencias nocivas de este potencial patógeno y representa un desafío importante para los pacientes y el personal de salud.

Palabras clave: Infecciones por Acinetobacter; Acinetobacter baumannii; infección hospitalaria; Vigilancia epidemiológica; Resistencia bacteriana

\begin{abstract}
Acinetobacter baumannii is considered as a bacterium of great clinical importance due to the resistance it has acquired to antimicrobials, which has triggered complications when referring an antibiotic therapy, prolonging the stay in the hospital of patients infected with this bacterium, causing a high degree of mortality due to its high proliferation capacity between different hospital areas. Objective. To describe the most relevant aspects about the epidemiology of the outbreaks caused by Acinetobacter baumannii in Latin America, as well as the different resistance mechanisms that this pathogen has acquired thus causing inconveniences when using the different therapeutic treatments. Materials and methods. a systematic review was carried out, under the PRISMA declaration, for the search of the information were used databases such as: Scielo, Redalyc, Google academic, 43 articles were found of which only 25 were valid for research. Results. The resistance of Acitetobacter baumannii to different antibiotic groups has increased over the years. This increase in resistance is due to several factors among which stand out: $\beta$-lactamases directed against beta-lactams, either broad spectrum or carbapenemases; variations in proteins of the outer membrane, ejection pumps, loss of porins, modifications of the place (target) of action of the antibiotics and alterations in the expression of penicillinfixing proteins. This ability depends in part on the ability of this bacterium to acquire resistance genes, often through horizontal gene transfer. Conclusions. A. baumannii has developed multiple antibiotic resistance mechanisms, which increase the harmful consequences of this potential pathogen and represents a major challenge for patients and health personnel.
\end{abstract}

Key words: Acinetobacter infections; Acinetobacter baumannii; hospital infection; Epidemiological surveillance; Bacterial resistance 


\section{RESUMO}

Acinetobacter baumannii é considerada como uma bactéria de grande importância clínica devido à resistência que adquiriu aos antimicrobianos, o que desencadeou complicações no momento de referir uma terapia antibiótica, prolongando a estadia na hospitalização dos pacientes infectados com esta bactéria, causando um elevado grau de mortalidade devido à sua elevada capacidade de proliferação entre diferentes áreas hospitalares. Objectivo. Descrever os aspectos mais relevantes sobre a epidemiologia dos surtos causados por Acinetobacter baumannii a nível da América Latina, bem como os diferentes mecanismos de resistência que adquiriu este patógeno causando com isto inconvenientes o momento de empregar os diferentes tratamentos terapéuticos. Material e métodos. Realizou-se uma revisão sistemática, sob a declaração PRISMA, para a busca da informação empregaram-se bases de dados como: Scielo, Redalyc, Google acadêmico, foram encontrados 43 artigos dos quais apenas 25 foram válidos para a pesquisa. Resultados. A resistência que apresenta Acitetobacter baumannii aos diferentes grupos de antibioticos aumentou com o passar dos anos. Este aumento da resistência deve-se a diversos factores, entre os quais se destacam: $\beta$-lactamases dirigidos contra os beta-lactâmicos, quer de largo espectro quer carbapenemases; variações nas proteínas da membrana externa, as bombas de expulsão, perda de porinas, modificações do local (branco) de acção dos antibioticos e alterações na expressão das proteínas fixadoras de penicilina. Esta capacidade depende em parte da capacidade desta bactéria para adquirir genes de resistência, muitas vezes através da transferência horizontal de genes. Conclusões: Acinetobacter baumannii desenvolveu múltiplos mecanismos de resistência aos antibióticos, o que aumentou as consequências nocivas deste potencial patogênico e representa um desafio importante para os pacientes e o pessoal de saúde.

Palavras-chave: Infecçōes por Acinetobacter; Acinetobacter baumannii; infecção hospitalar; Vigilância epidemiológica; Resistência bacteriana

\section{INTRODUCCIÓN}

Las infecciones nosocomiales se propagan frecuentemente y con rapidez en heridas quirúrgicas, vías respiratorias y urinarias. Según datos publicados por la OMS, el 8,7\% de pacientes que se encuentran hospitalizados padecenestetipo deinfeccionesyporlogeneral ocurren en la unidad de cuidados intensivos. Estas tasas de prevalencia son mayores en casos de pacientes inmunodeprimidos, con procesos invasivos o de edad avanzada (1-3).
Los microorganismos causantes de estas infecciones son oportunistas y constituyen un grave problema de salud tanto con afectación para los pacientes, como para el personal sanitario y comunidad en general $(4,5)$.

El mayor problema para el aumento de la mortalidad a causa de estas infecciones es la aparición de la resistencia a múltiples antibióticos de uso común y hospitalario, esta resistencia ocurre a causa del uso inadecuado de las terapias antibióticas; estas altas tasas de resistencia conllevan al aumento de la morbimortalidad y la estancia hospitalaria $(6,7)$.

La Acinetobacter baumannii (A. baumannii) es un cocobacilo aerobio gramnegativo que puede contaminar tanto los instrumentos sanitarios como las superficies hospitalarias. Las infecciones causadas por esta bacteria han aumentado sobre todo en pacientes hospitalizados en el área de cuidados intensivos, así como también en la población de pacientes con su sistema inmunológico deprimido. Esta situación actual constituye un serio problema para el personal de salud en el momento de realizar una prescripción $(8,9)$.

Actualmente la $A$. baumannii se ha convertido en uno de los microorganismos principales causantes de infecciones nosocomiales graves, las cuales incluyen: infecciones de piel, heridas y tejidos blandos, hasta infecciones del aparato urinario, pudiendo agravarse a meningitis secundaria. Sin embargo, dentro las infecciones más relevantes con altas tasas de mortalidad generadas por esta bacteria son la neumonía 
asociada al ventilador y las infecciones del torrente sanguíneo $(3,7,8)$.

En Latinoamérica, la resistencia antimicrobiana constituye un limitante para establecer un tratamiento efectivo, las elevadas y crecientes tasas de resistencia a diferentes antibióticos representan en la actualidad una amenaza sobre todo a nivel hospitalario (12). En este problema se incluyen bacterias de alta importancia clínica entre las que se encuentran Staphylococcus aureus (S. aureus) meticilino resistente, Pseudomona aeruginosa, Enterobacteriaceae productoras de $\beta$-lactamasas de amplio espectro y la $A$. baumannii resistente a los carbapenémicos $(13,14)$.

Los bacilos gram negativos presentan múltiples mecanismos de resistencia, los cuales están determinados por mutaciones cromosómicas y la aparición de genes transferibles. El mecanismo de mayor importancia es el de la producción de betalactamasas de amplio espectro, las inducibles tipo Amp-C y las carbapenemasas (15).

Por otro lado, se ha logrado aislar en la A. baumannii enzimas de tipo carbapenemasas, siendo la enzima OXA-23 una de las más frecuentes (15). Entre otro de los mecanismos de resistencia resaltan la variación de los transportadores de membrana, principalmente de tipo porina por una afectación en la permeabilidad de las mismas y con ello, la expresión de las bombas de salida o expulsión $(9,16)$. Estos mecanismos de resistencia son considerados como mecanismos moleculares de resistencia.
De igual manera también se mencionan modificaciones en el lugar de acción de los antibióticos y alteraciones en la expresión de las proteínas ligadoras de penicilina (principalmente en el caso de bacterias grampositivas) (17). En el caso de los aminoglucósidos, las tetraciclinas y las quinolonas, las bacterias presentan un mecanismo de acción afectado debido a una resistencia adquirida por esta misma bacteria $(7,8)$. Esta adquisición se sospecha que fue a través de un mecanismo horizontal de genes.

En general, la A. baumannii ha adquirido resistencia a una amplia cantidad de antimicrobianos en las últimas décadas, se ha caracterizado por ser la causante del 90 - 92 $\%$ de infecciones nosocomiales. Se considera que esta capacidad de desarrollar resistencia depende de la bacteria para adquirir genes de resistencia, a menudo a través de una transferencia horizontal de genes a partir de otras bacterias (18). Estudios recientes sugieren fuertemente que la adquisición del fenotipo MDR es un factor decisivo para el éxito de la $A$. baumannii como patógeno nosocomial $(10,19)$.

Según una investigación efectuada por la Sociedad Española de Medicina Intensiva, Crítica y Unidades Coronarias (específicamente el grupo de Enfermedades e Infecciones) sobre la resistencia a antibióticos que ha desarrollado la A. baumannii, la sitúa entre los primeros lugares en la generación de infecciones intrahospitalarias, en especial en pacientes hospitalizados en la Unidad de Cuidados Intensivos (UCl). Este estudio permitió analizar la evolución de los diferentes mecanismos de resistencia; así como también 
las diversas estrategias que se pueden plantear para prevenir y controlar las infecciones nosocomiales causadas por la $\mathrm{A}$. baumannii. $(20,21)$.

\section{METODOLOGÍA}

Esta investigación es una revisión sistemática con un diseño documental. Se fundamenta en la búsqueda, evaluación y selección de artículos científicos relacionados con la vigilancia epidemiológica de la A. baumannii multirresistente en ambientes intrahospitalarios.

La recolección de la información se realizó a través de las bases de datos de revistas indexadas como, Google Académico, ScieLO, Dialnet, Redalyc, Scopus, Taylor\&Francis, Web of Science y Pubmed. Se incluyeron artículos científicos originales, tanto en español como e inglés dentro del periodo 2010-2020. Se encontraron 60 artículos de los cuales, solo 45 cumplieron con los criterios de inclusión. Se emplearon restricciones respecto al periodo de tiempo de evaluación.

Para realizar la búsqueda de toda la información empleada en el artículo se utilizaron palabras clave como: infecciones nosocomiales, resistencia antimicrobiana, cultivos bacterias multirresistentes, bacterias nosocomiales, cultivos epidemiológicos, Acinetobacter baumannii, Acinetobacter multirresistente, Acinetobacter e infecciones intrahospitalarias, epidemiología Acinetobacter baumannii. Así como también se emplearon conectores booleanos como: $y, o$ (and- or).

Se revisaron los artículos de manera independiente y luego se procedió a realizar una evaluación y análisis de los mismos para su posterior comparación en conjunto. Los artículos seleccionados se identificaron con base en los títulos, año, resúmenes, discusión y conclusiones. Los estudios utilizados se evaluaron con base en el grado de resistencia antimicrobiana, la propagación de la bacteria en ambientes hospitalarios, su incidencia en el área de $\mathrm{UCl}$ y el aumento de esta resistencia con el transcurso de los años. Se realizó una revisión sistemática para combinar los resultados obtenidos de las investigaciones realizadas de manera individual.

Criterios de inclusión. Se consideraron investigaciones que indicaron tasas de morbilidad y de mortalidad, mecanismos de resistencia y prevalencia de la Acinetobacter baumannii en pacientes 0 en superficies hospitalarias, así como también estudios que se hayan publicado en español o inglés dentro del periodo de tiempo establecido.

Criterios de exclusión. No se consideraron dentro de esta investigación artículos científicos en cuya investigación no se evidenciaban tasas de morbilidad, mortalidad, mecanismos de resistencia o prevalencia de la Acinetobacter baumannii en pacientes o en superficies hospitalarias. Tampoco se fueron considerados estudios que se hayan publicado en otro idioma que no fuera inglés o español o fuera del periodo de tiempo establecido.

De la búsqueda en general se encontraron 60 artículos, de los cuales, cinco eran duplicados, los demás fueron analizados para en lo posterior descartar cinco más de acuerdo con los criterios de exclusión. Se culminó la 
revisión y selección de los artículos realizando una lectura completa de cada uno de ellos y se excluyeron cinco artículos por discrepancias en los métodos, en los resultados o en el estudio en general. Finalmente se realizó la revisión sistemática con los 47 artículos restantes.
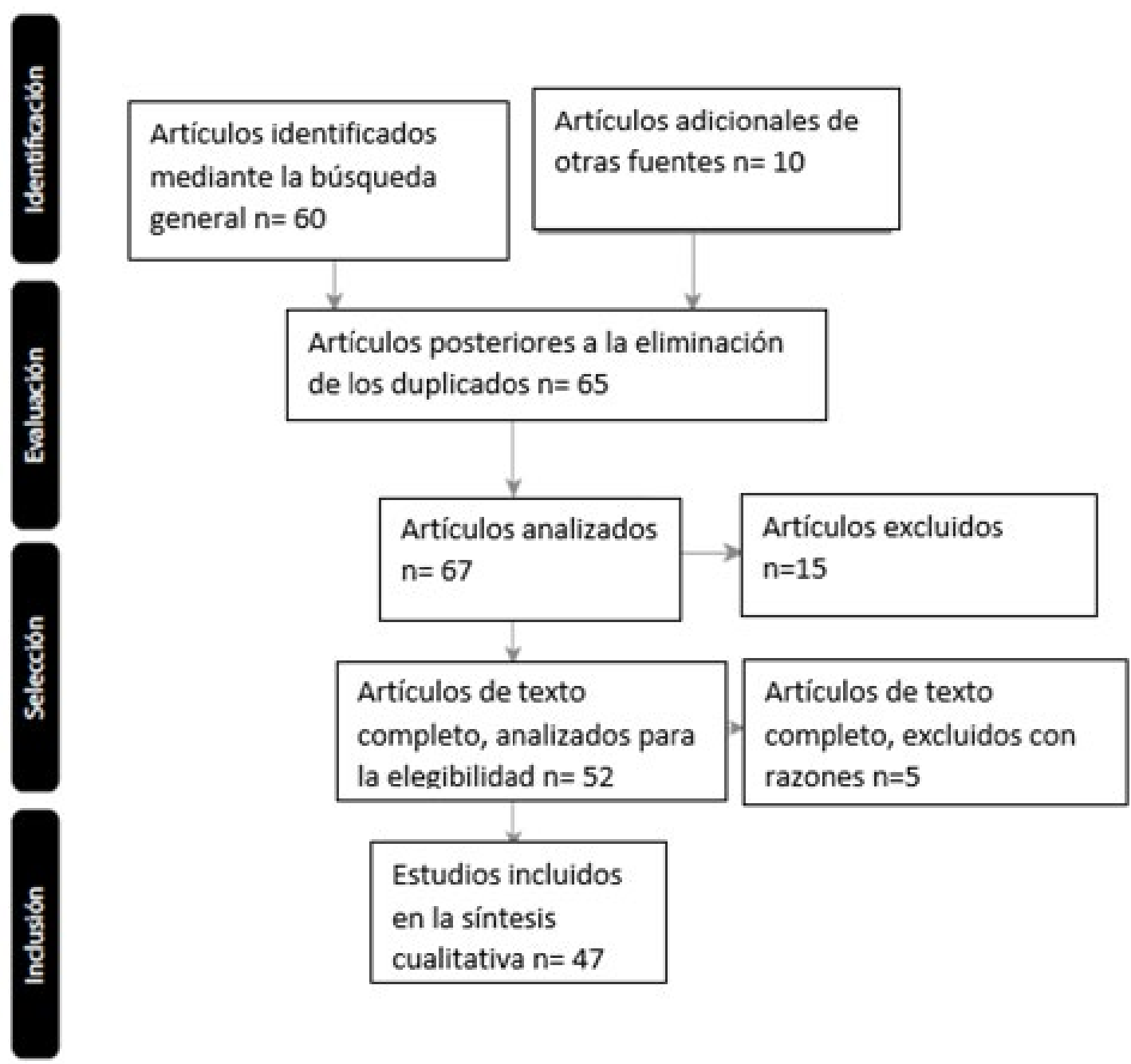

Figura 1. Diagrama de flujo de Prisma (22).

\section{RESULTADOS Y DISCUSIÓN}

Para evaluar la tasa de resistencia de la $A$. baumannii frente a los antibióticos de uso común se realizó una amplia búsqueda, tomando en cuenta información que llevó a conocer como ha incrementado la multirresistencia durante los últimos años. Las estrategias de búsqueda de información se detallan en la Tabla 1. 
Tabla 1. Estrategia de búsqueda de información.

\begin{tabular}{|c|c|c|c|c|}
\hline $\begin{array}{l}\text { Base de datos } \\
\text { buscador }\end{array}$ & Palabras clave & $\begin{array}{c}\text { Marcadores } \\
\text { booleanos }\end{array}$ & Limitadores & Artículos \\
\hline Scielo & $\begin{array}{l}\text { Acinetobacter baumannii, } \\
\text { Multirresistencia, } \\
\text { Infecciones nosocomiales } \\
\text { Resistencia bacteriana }\end{array}$ & "y-o" & $\begin{array}{l}\text { - Texto completo } \\
\text { - Texto completo gratis }\end{array}$ & 29 \\
\hline Medigraphic & $\begin{array}{l}\text { Acinetobacter baumannii, } \\
\text { Multirresistencia, } \\
\text { Infecciones nosocomiales } \\
\text { Resistencia bacteriana }\end{array}$ & "y-o" & $\begin{array}{l}\text { - Texto completo } \\
\text { - Texto completo gratis }\end{array}$ & 3 \\
\hline Pubmed & $\begin{array}{l}\text { Acinetobacter baumannii, } \\
\text { Multirresistencia, } \\
\text { Infecciones nosocomiales } \\
\text { Resistencia bacteriana }\end{array}$ & "y-o" & $\begin{array}{l}\text { - Texto completo } \\
\text { - Texto completo gratis }\end{array}$ & 7 \\
\hline ScienceDirect & $\begin{array}{l}\text { Acinetobacter baumannii, } \\
\text { Multirresistencia, } \\
\text { Infecciones nosocomiales } \\
\text { Resistencia bacteriana }\end{array}$ & "y-o" & $\begin{array}{l}\text { - Texto completo } \\
\text { - Texto completo gratis }\end{array}$ & 6 \\
\hline Redalyc & $\begin{array}{l}\text { Acinetobacter baumannii, } \\
\text { Multirresistencia, } \\
\text { Infecciones nosocomiales } \\
\text { Resistencia bacteriana }\end{array}$ & “y-o" & $\begin{array}{l}\text { - Texto completo } \\
\text { - Texto completo gratis }\end{array}$ & 2 \\
\hline
\end{tabular}

Dentro del grupo de los antibióticos a los que ha presentado mayor tasa de resistencia se destacan ticarcilina / ácido clavulánico, cefepime, meropenem, imipenem, gentamicina, amikacina, ciprofloxacino, ceftazidime. Esta resistencia constituye una gran limitante el momento de realizar una prescripción. El aumento de la resistencia presentada por la A. baumannii desde al año 2010 al 2015 ha sido bastante significativa y creciente, lo cual genera complicaciones causando de esta forma infecciones nosocomiales severas y constituye de esa manera un limitante el momento de realizar una prescripción o efectuar un tratamiento.

La resistencia que ha adquirido la $A$. baumannii durante el periodo de 2010 al 2015, según los datos obtenidos provenientes de las diferentes investigaciones, señalan que la resistencia de la bacteria ha aumentado en el periodo de cinco años a partir de las muestras obtenidas en los hospitales a nivel mundial hasta llegar a observarse en la mayoría de los casos del $100 \%$, tal como se observa en la Tabla 2. 
Tabla 2. Resistencia a antibióticos desarrollado por A. baumannii en el periodo 2010-2015.

\begin{tabular}{|c|c|c|c|c|c|c|}
\hline Antibiótico & 2010 & 2011 & 2012 & 2013 & 2014 & 2015 \\
\hline Cefepime & $77,80 \%$ & $72 \%$ & $87 \%$ & $59,60 \%$ & $82,10 \%$ & $100 \%$ \\
\hline Ceftazidima & $66,70 \%$ & $76 \%$ & $87,50 \%$ & $61 \%$ & $14,30 \%$ & $100 \%$ \\
\hline Piperacilina/tazobactam & $100 \%$ & & & $63,30 \%$ & & $99 \%$ \\
\hline Ampicilina/sulbactam & & & & & & $94,2 \%$ \\
\hline Ciprofloxacino & & & & & & $80 \%$ \\
\hline Gentamicina & $100 \%$ & & & $59,60 \%$ & & $100 \%$ \\
\hline Tigeciclina & & & & & & $21,2 \%$ \\
\hline Colistina & & & & & & $3,20 \%$ \\
\hline Imipenem & $82,50 \%$ & & & $59,30 \%$ & & $100 \%$ \\
\hline Meropenem & $90 \%$ & & & & & $100 \%$ \\
\hline Ampicilina & $100 \%$ & & & & & \\
\hline Ticarcilina/ac. Clavulánico & $98,60 \%$ & & & $62,90 \%$ & & $100 \%$ \\
\hline Ticarcilina/taxobactam & $66,70 \%$ & & & & & \\
\hline Ceftriaxona & $98,60 \%$ & $88 \%$ & $87,50 \%$ & $62,90 \%$ & & \\
\hline Amikacina & $63 \%$ & $76 \%$ & $87,50 \%$ & & & $100 \%$ \\
\hline Ciprofloxacino & $100 \%$ & $76 \%$ & $91,30 \%$ & $65,80 \%$ & & $98,10 \%$ \\
\hline Tobramicina & & & & $56,50 \%$ & & $100 \%$ \\
\hline Trimetropin/sulfametozaxol & & & & $59,90 \%$ & & $100 \%$ \\
\hline Levofloxacino & $70 \%$ & $72 \%$ & $83,30 \%$ & $46 \%$ & & $90,40 \%$ \\
\hline Sulperazona & $100 \%$ & & & & & \\
\hline Aztreonam & $82,30 \%$ & & & & & \\
\hline Mezlocilina & & & & $78,50 \%$ & & \\
\hline Cefotaxima & & & & $69,10 \%$ & & \\
\hline Tetraciclina & & & & $60,70 \%$ & & \\
\hline Doxiciclina & & & & $59,60 \%$ & & \\
\hline
\end{tabular}

Los resultados obtenidos en la plataforma SciELo (Tabla 3) identificaron cuatro investigaciones, en su mayoría provenientes de
Colombia, en donde se evidencia la resistencia de $A$. baumannii a los antibióticos de uso hospitalario, incluyendo los carbapenémicos. 
Tabla 3. Resultados obtenidos a partir de la búsqueda por plataforma: SciELo.

\begin{tabular}{|c|c|c|c|c|c|c|c|}
\hline $\mathbf{N}^{\circ}$ & Año & Autor & Resumen & Tipo de estudio & Lugar & Población & Resultados \\
\hline 1 & 2014 & $\begin{array}{l}\text { Prado } \\
\text { et. al (23). }\end{array}$ & $\begin{array}{l}\text { Estudio sobre la } \\
\text { caracterización fenotípica } \\
\text { de los aislamientos } \\
\text { obtenidos en lo que se } \\
\text { identificó la A. baumannii } \\
\text { en una institución de salud } \\
\text { en Cali. }\end{array}$ & $\begin{array}{l}\text { Estudio } \\
\text { epidemiológico, } \\
\text { observacional de } \\
\text { tipo transversal }\end{array}$ & $\begin{array}{l}\text { Cali, } \\
\text { Colombia }\end{array}$ & $\begin{array}{l}\text { Pacientes hospitalizados que } \\
\text { presentaron infección causada por la } \\
\text { A. baumannii }\end{array}$ & $\begin{array}{l}\text { Resistencia: } \\
\text { - Cefepime: } 82,1 \% \\
\text { - Ceftazidime: } 14,3 \% \\
\text { Sensibilidad: } \\
\text { - Ceftazidime: } 50 \% \\
\text { - En uno de los aislamientos se observó } \\
\text { sensibilidad a la Ciprofloxacina (23) }\end{array}$ \\
\hline 2 & 2015 & $\begin{array}{l}\text { Vanegas } \\
\text { et. al (24). }\end{array}$ & $\begin{array}{l}\text { Análisis acerca de la } \\
\text { resistencia de la A. } \\
\text { baumannii frente al grupo } \\
\text { de carbapenémicos. } \\
\text { Las muestras fueron } \\
\text { obtenidas a partir de } \\
\text { pacientes que padecían } \\
\text { osteomielitis, infecciones } \\
\text { de tejidos blandos o de la } \\
\text { piel en varios hospitales } \\
\text { de Medellín. }\end{array}$ & $\begin{array}{l}\text { Estudio } \\
\text { epidemiológico, } \\
\text { observacional de } \\
\text { tipo transversal }\end{array}$ & $\begin{array}{l}\text { Hospitales } \\
\text { de Medellín, } \\
\text { Colombia }\end{array}$ & $\begin{array}{l}\text { Pacientes que presentaron } \\
\text { infecciones en la piel, en tejidos } \\
\text { blandos y osteomielitis }\end{array}$ & $\begin{array}{l}\text { - } 32 \text { pacientes presentaron infección causada } \\
\text { por la A. baumannii, observándose resistencia a } \\
\text { carbapenémicos. } \\
\text { - Los antibióticos más empleados en el análisis } \\
\text { fueron: piperacilina- tazobactam junto con } \\
\text { carbapenémicos en un } 48 \% \text {. Más del } 50 \% \text { de los } \\
\text { pacientes estaban hospitalizados en UCl y otras } \\
\text { salas diferentes. } \\
\text { - Resistencia superior al } 80 \% \text { para los } \beta \text { - } \\
\text { lactámicos con los que se realizó el análisis. } \\
\text { Dicho estudio también incluyó ampicilina/ } \\
\text { sulbactam, piperacilina-tazobactam, cefepimey } \\
\text { ceftazidima, así como también otros antibióticos } \\
\text { como ciprofloxacina y gentamicina. Por otro } \\
\text { lado, se observó resistencia a la tigeciclina } \\
\text { con un } 3,4 \% \text {, así como también Resistencia a la } \\
\text { colistina con un } 3,2 \% \text {. } \\
\text { - También se observó Resistencia en un } 100 \% \text { al } \\
\text { meropenem e imipenem (24). }\end{array}$ \\
\hline
\end{tabular}




\begin{tabular}{|c|c|c|c|c|c|c|c|}
\hline $\mathbf{N}^{\circ}$ & Año & Autor & Resumen & Tipo de estudio & Lugar & Población & Resultados \\
\hline
\end{tabular}

\section{Higgins et.} al (25).

Investigación acerca de la propagación a nivel mundial de la A. baumannii que presentan resistencia a los carbapenémicos.
Estudio

epidemiológico, observacional de tipo transversal Norte y Latina,

Europa, Asia, Sudáfrica y Australia

Los aislados se agruparon en ocho Entre los 515 de A. baumannii, se confirmó: grupos distintos, incluidos los clones europeos I, II y III. El clon europeo II fue el más grande (246 aislados) y el grupo más extendido (Estados Unidos, Europa, Israel, Asia, Australia y Sudáfrica

471 aislados eran resistentes al imipenem, 21 eran intermedios y 23 eran susceptibles.

- La susceptibilidad a los $\beta$-lactámicos no carbapenémicos, incluidos aquellos con un inhibidor de $\beta$-lactamasas, fue baja, con un $5 \%$ de aislados susceptibles.

- Susceptibilidad a la amikacina fue del $35 \%$

- Tigeciclina y la minociclina tuvieron alta actividad, con. $80 \%$ de los aislados registrados como susceptibles (25).

- Se obtuvieron 24 aislamientos (46,2\%) que se obtuvieron a partir de muestreo nasal. Por otro lado, 12 aislamientos $(23,1 \%)$ se obtuvieron de herida quirúrgica, $6(11,5 \%)$ fueron obtenidos a partir de punta de catéter, 8 aislamientos (11,5\%) a partir de orina y sangre y dos aislamientos $(3,8 \%)$ provenientes de secreción uretral.

- $-100 \%$ de los aislamientos en donde se confirmó la presencia de la A. baumannii se observó resistencia a diferentes antibióticos como: amikacina, tobramicina, gentamicina, cefepime, ceftazidina, trimetoprim/sulfametoxazol, imipenem y ticarcilina/ clavulanato. 


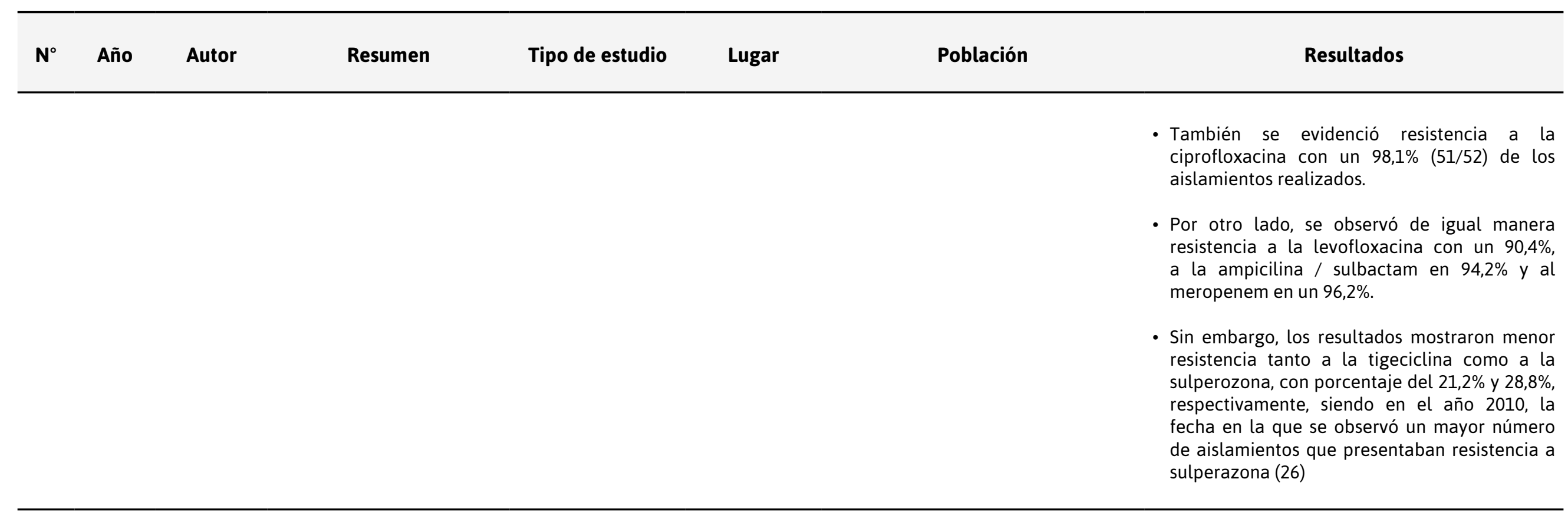

De igual manera, a través de la plataforma Pubmed se verificó cuatro investigaciones que relacionan la resistencia de A. baumannii a antibióticos. Dos de dichas investigaciones resaltan la importancia de la formación de una biopelícula como mecanismo de supervivencia frente a condiciones ambientales adversas por parte de la bacteria (Tabla 4). 
Tabla 4. Resultados obtenidos a partir de la búsqueda por plataforma: Pubmed.

\begin{tabular}{|c|c|c|c|c|c|c|c|}
\hline $\mathbf{N}^{\circ}$ & Año & Autor & Resumen & Tipo de estudio & Lugar & Población & Resultados \\
\hline 1 & 201 & $\begin{array}{l}\text { Hart et. al } \\
(16)\end{array}$ & $\begin{array}{l}\text { Se investigó la resistencia a } \\
\text { diferentes antibióticos que } \\
\text { presenta la A. baumannii } \\
\text { en muestras aisladas en el } \\
\text { primer trimestre del } 2010 \\
\text { en el Hospital "Hermanos } \\
\text { Ameijeiras" }\end{array}$ & $\begin{array}{l}\text { Estudio } \\
\text { epidemiológico, } \\
\text { observacional de } \\
\text { tipo transversal }\end{array}$ & $\begin{array}{l}\text { La Habana, } \\
\text { Cuba }\end{array}$ & $\begin{array}{l}40 \text { pacientes del hospital } \\
\text { Hospital Clínico quirúrgico } \\
\text { "Hermanos Ameijeiras" }\end{array}$ & $\begin{array}{l}\text { - Se observó } 100 \% \text { de resistencia frente al ampicilina. } \\
\text { a la ticarcillina junto con á. clavulánico. De igual manera, } \\
\text { resistencia en el } 66,7 \% \text { para la ticarcillina-tazobactam. } \\
\text { - La resistencia a las cefalosporinas de tercera y cuarta } \\
\text { generación resultó ser de un } 98,6 \% \text { para ceftriaxona y } 77,8 \% \\
\text { para cefepime. } \\
\text { - Los carbapenémicos también presentaron en un } 90 \% \text { de } \\
\text { los casos de resistencia, específicamente para el caso del } \\
\text { meropenem y } 82,5 \% \text { para el caso del imipenem. } \\
\text { - Con los aminoglucósidos se observó elevada resistencia } \\
\text { para: gentamicina, amikacina, ciprofloxacina. Sin embargo, } \\
\text { se evidenció } 100 \% \text { de sensibilidad frente a la tigeciclina, y } \\
\text { colistina del total de muestrasidentificadas de la A. baumannii } \\
\text { (16). }\end{array}$ \\
\hline 2 & 2015 & $\begin{array}{l}\text { Zeighami } \\
\text { et. al (28). }\end{array}$ & $\begin{array}{l}\text { En el estudio se observaron } \\
\text { las características de } \\
\text { virulencia de la biopelícula } \\
\text { multirresistente que forma } \\
\text { la A. baumannii aislada } \\
\text { de pacientes del área de } \\
\text { cuidados intensivos }\end{array}$ & $\begin{array}{l}\text { Estudio } \\
\text { epidemiológico } \\
\text { observacional } \\
\text { de tipo } \\
\text { transversal. }\end{array}$ & & $\begin{array}{l}100 \text { aislamientos } \\
\text { clínicos de la } \mathrm{A} \text {. } \\
\text { baumannii de pacientes } \\
\text { inmunodeprimido } \\
\text { hospitalizados en } \mathrm{UCl}\end{array}$ & $\begin{array}{l}\text { Resistencia: } \\
\text { - -Ciprofloxacina e imipenem } 100 \% \\
\text { - -Piperacilina } 99 \% \\
\text { - -Cefepime / levofloxacina / ceftazidima } 97 \% \text { ) } \\
\text { - El patrón más prevalente fue la resistencia que presentó } \\
\text { frente a la ampicilina/sulbactam, ceftazidima, imipenem, } \\
\text { tobramicina, gentamicina, doxiciclina, levofloxacina, } \\
\text { ciprofloxacina, cotrimoxazol, pipercilina-cefepima con un } \\
32 \% \text { de frecuencia (28) }\end{array}$ \\
\hline
\end{tabular}

Revista de Investigación en Salud 


\begin{tabular}{|c|c|c|c|c|c|c|c|}
\hline $\mathbf{N}^{\circ}$ & Año & Autor & Resumen & Tipo de estudio & Lugar & Población & Resultados \\
\hline 1 & 201 & $\begin{array}{l}\text { Hart et. al } \\
(16)\end{array}$ & $\begin{array}{l}\text { Se investigó la resistencia a } \\
\text { diferentes antibióticos que } \\
\text { presenta la } A \text {. baumannii } \\
\text { en muestras aisladas en el } \\
\text { primer trimestre del } 2010 \\
\text { en el Hospital "Hermanos } \\
\text { Ameijeiras" }\end{array}$ & $\begin{array}{l}\text { Estudio } \\
\text { epidemiológico, } \\
\text { observacional de } \\
\text { tipo transversal }\end{array}$ & $\begin{array}{l}\text { La Habana, } \\
\text { Cuba }\end{array}$ & $\begin{array}{l}40 \text { pacientes del hospital } \\
\text { Hospital Clínico quirúrgico } \\
\text { "Hermanos Ameijeiras" }\end{array}$ & $\begin{array}{l}\text { Se observó resistencia a: } \\
\text { - Mezlocilina } 78,3 \% \\
\text { - Cefotaxima } 69,1 \% \\
\text { - Ciprofloxacina } 65,8 \% \\
\text { - Piperacilina } 63,6 \% \\
\text { - Ticarcilina / ácido clavulánico } 62,9 \% \\
\text { - Ceftriaxona } 62,9 \% \\
\text { - Ceftazidima } 61,0 \% \\
\text { - Tetraciclina } 60,7 \% \\
\text { - Trimetoprima / sulfametoxazol 59,9\% } \\
\text { - Gentamicina } 59,6 \% \\
\text { - Cefepime } 59,6 \% \\
\text { - Doxiciclina } 59,6 \% \\
\text { - Imipenem } 59,2 \% \\
\text { - Meropenem } 59,2 \% \\
\text { - Ampicilina / sulbactam } 58,1 \% \\
\text { - Tobramicina } 56,6 \% \\
\text { - Piperacilina / tazobactam } 48,9 \% \\
\text { - Levofloxacina } 46,0 \% \\
\text { - Minociclina } 28,3 \% \\
\text { - Amikacina } 22,4 \% \\
\text { - Polimixina B } 3,7 \%(29)\end{array}$ \\
\hline 4 & 2015 & $\begin{array}{l}\text { Deylam } \\
\text { et. al (30). }\end{array}$ & $\begin{array}{l}\text { El artículo señala la } \\
\text { resistencia que se genera } \\
\text { frente a antibióticos } \\
\text { mediada por integrones en } \\
\text { la A. baumannii aislado de } \\
\text { pacientes hospitalizados } \\
\text { en el área de cuidados } \\
\text { intensivos, en Irán. }\end{array}$ & $\begin{array}{l}\text { Estudio } \\
\text { epidemiológico } \\
\text { observacional de } \\
\text { tipo transversal }\end{array}$ & Irán & $\begin{array}{l}73 \text { muestras obtenidas } \\
\text { de pacientes de UCI de } \\
\text { un hospital de Babol, } \\
\text { Irán. }\end{array}$ & $\begin{array}{l}\text { - Se observó resistencia frente a: } \\
\text { - }- \text { Amikacina } 91,4 \% \\
\text { - }- \text { Gentamicina } 85,7 \% \\
\text { - }- \text { Ciprofloxacino } 94,3 \% \\
\text { - }- \text { Ceftazidima } 100 \% \\
\text { - }- \text { Imipenem } 94.3 \% \\
\text { - }- \text { Meropenem } 94,3 \% \\
\text { - }- \text { Piperacilina/tazobactam } 91,4 \%(30) \text {. }\end{array}$ \\
\hline
\end{tabular}

Revista de Investigación en Salud 
Mediante la Tabla 5 se observa la resistencia de la A. baumannii frente a diferentes antibióticos, incluyendo $\beta$-lactámicos y cefalosporinas durante un periodo de tiempo de dos años a partir del 2010. En el mismo cuadro se observa la disminución en los porcentajes de sensibilidad frente a los mismos antibióticos durante la duración de la investigación.

Tabla 5. Resultados obtenidos a partir de la búsqueda por plataforma: Medigraphic

\begin{tabular}{|c|c|c|c|c|c|c|c|}
\hline $\mathbf{N}^{\circ}$ & Año & Autor & Resumen & Tipo de estudio & Lugar & Población & Resultados \\
\hline 1 & 2010 & $\begin{array}{l}\text { Rincón- } \\
\text { León y } \\
\text { Navarro- } \\
\text { Fuentes } \\
\text { (27). }\end{array}$ & $\begin{array}{l}\text { En el artículo se verificó la } \\
\text { tendencia de resistencia } \\
\text { a los antimicrobianos } \\
\text { en diferentes patógenos } \\
\text { aislados provenientes de } \\
\text { infecciones nosocomiales. }\end{array}$ & $\begin{array}{l}\text { Estudio } \\
\text { epidemiológico } \\
\text { observacional de } \\
\text { tipo transversal }\end{array}$ & Chiapas & $\begin{array}{l}\text { Pacientes } \\
\text { hospitalizados en } \\
\text { el Hospital de Alta } \\
\text { Especialidad Ciudad } \\
\text { Salud, en el periodo de } \\
\text { tiempo 2009/2012. }\end{array}$ & $\begin{array}{l}\text { Resistencia: } \\
\text { - Amikacina: 2010- 63.3\%,2011- 76\%, } 2012-87,5 \% \\
\text { - Aztreonam: } 2010-82,3 \% \\
\text { - Piperacilina/tazobactam:2010- 100\% } \\
\text { - Cefepime: } 2010-63,3 \%, 2011-72,2012-87 \% \\
\text { - Ceftazidima: } 2010-66.7 \%, 2011-76 \%, 2012-87,5 \% \\
\text { - Ceftriaxona: } 2010-70,2011-88 \%, 2012-87,5 \% \\
\text { - Ciprofloxacino: } 2010-70 \%, 2011-76 \%, 2012-91,3 \% \\
\text { - Levofloxacino: } 2010-70 \%, 2011-72 \%, 2012-83,3 \% \\
\text { - Imipenem:2010- } 10 \% \\
\text { - Meropenem:2010-3,8\%, 2011-4,5\%, 2012- 4,3\% (27) }\end{array}$ \\
\hline
\end{tabular}

Revista de Investigación en Salud 
El Gráfico 1 permite verificar la tasa de variabilidad de los porcentajes de resistencia de la A. baumannii frente a los diferentes antibióticos durante el periodo 2010-2015. Se observa que la resistencia es variable, llegando a verificar resistencia algunos de ellos, incluyendo cefalosporinas y betalactàmicos.

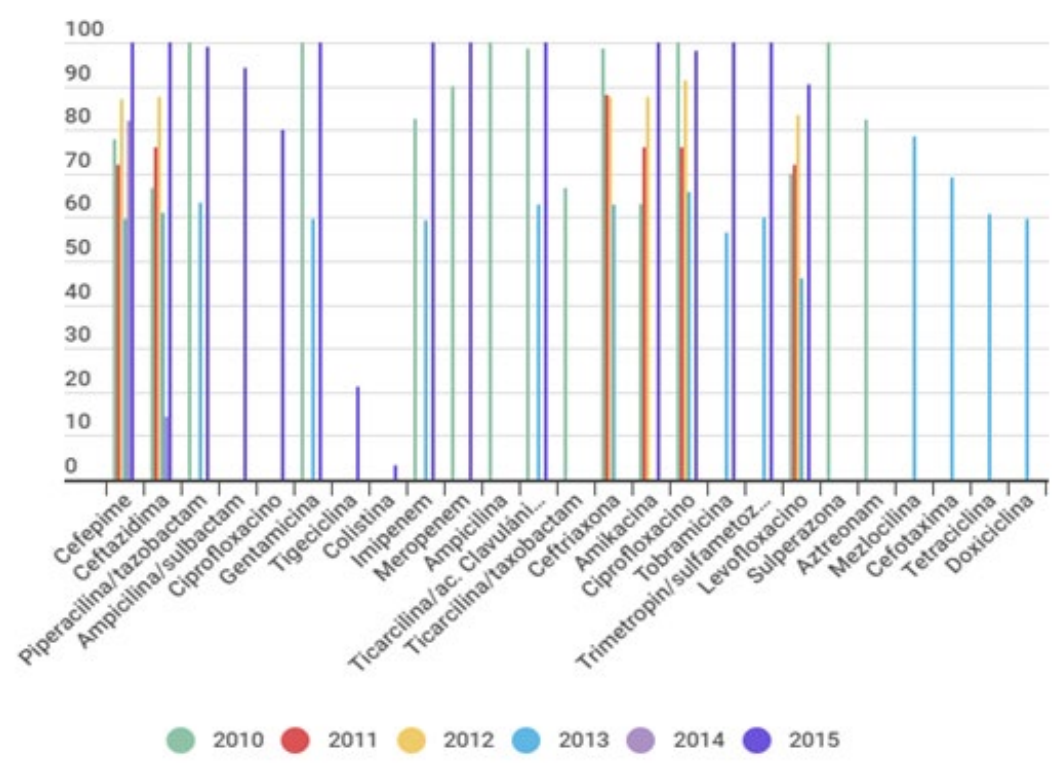

Gráfico 1. Tasa de variabilidad de resistencia de la A. baumannii a antibióticos durante el periodo 2010-2015.

El Gráfico 2 demuestra la capacidad de ceftazidima, amikacina, gentamicina, la A. baumannii para adquirir resistencia a imipenem, meropenem, ampicilna, ticarcilinalos diferentes antibióticos en los cinco años, ácido clavulánico, tobramicina y trimetoprim alcanzando total resistencia con cefepime, sulfametoxazol.

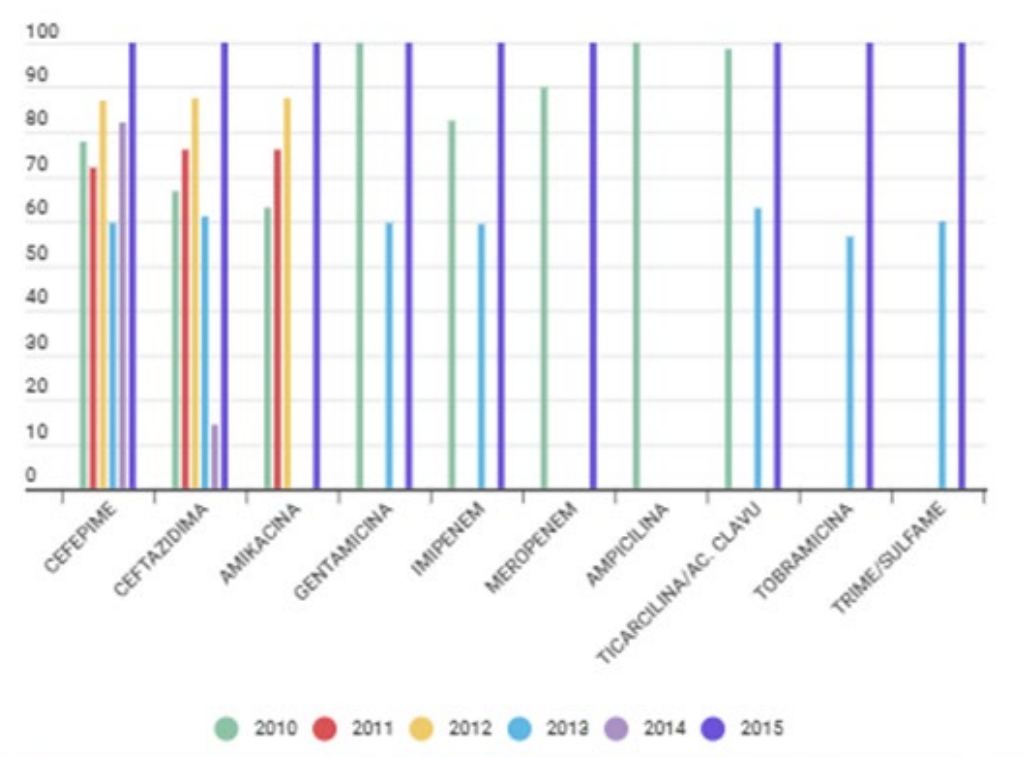

Gráfico 2. Resistencia de la Acinetobacter baumannii alcanzada al 100\% frente a antibióticos en el periodo 2010-2015. 


\section{Discusión}

Las infecciones nosocomiales se han convertido en un verdadero reto a nivel hospitalario ya que constituyen las causas principales de aumento de mortalidad, morbilidad y de la prolongación en la estancia de los pacientes, en especial en el área de $\mathrm{UCl}$. El aumento de esta resistencia bacteriana es debido principalmente al uso prolongado o inadecuado de antibióticos o fallas en la asepsia. Las bacterias nosocomiales se han convertido en microorganismos con alta resistencia a antimicrobianos, generando un serio problema de salud, tanto a nivel público y privado de muchos países $(27,31)$.

Las bacterias nosocomiales son microorganismos oportunistas que pueden sobrevivir a las condiciones ambientales en las diferentes áreas y superficies de hospitales, al momento que ingresan al cuerpo humano aprovechan la fragilidad y susceptibilidad inmunológica del paciente para invadir y causar daño en su organismo (4).

América Latina presenta una de las mayores incidencias de brotes generados por bacterias nosocomiales multirresistentes. Durante las últimas décadas se ha verificado un aumento en el interés por verificar los mecanismos de resistencia de las bacterias frente a las diferentes familias de antibióticos de uso común y de uso hospitalario (32).

De igual manera, la resistencia a los antibióticos ha aumentado con el tiempo y se ha observado que los mecanismos de resistencia se han perfeccionado poco a poco, resultando un mecanismo de defensa para sobrevivir frente al efecto de estos (33).
Por lo tanto, la $A$. baumannii se ha convertido en uno de los agentes patógenos causantes del mayor número de infecciones nosocomiales adquiridas en los hospitales, debido al aumento en la prevalencia de dichas infecciones. En la actualidad resulta reducida la cantidad de antibióticos efectivos para tratar las infecciones causadas por esta bacteria. La acumulación de varios mecanismos de resistencia ha provocado una reducción en la cantidad de antibióticos que podrían ser utilizados en tratamiento para infecciones causadas por la $A$. baumannii en la práctica clínica $(34,35)$.

La $A$. baumannii ha aumentado su prevalencia y morbilidad en infecciones nosocomiales. De igual manera ha sucedido consus mecanismos de resistencia yadaptación al medio ambiente. En España, según el Estudio Nacional de Vigilancia en Infección Nosocomial, la bacteria ocupa el primer lugar como agente causal de infecciones intrahospitalarias que pueden afectar a pacientes ingresados en las diferentes áreas hospitalarias pero principalmente se observa con mayor frecuencia en Cuidados Intensivos (36).

Como se mencionó anteriormente, la $A$. baumannii posee diferentes mecanismos de resistencia que le permiten eludir la acción de un antibiótico. Entre los mecanismos principales se podrían sospechar el desarrollo de $\beta$-lactamasas, lo que le permite adquirir resistencia a la familia de antibióticos $\beta$-lactámicos como penicilinas, carbapenémicos o monobactámicos, entre otros, circunstancia que se observa en las 
investigaciones planteadas desde el 2010 y podría explicar la resistencia a diferentes tipos de antibióticos (37).

Otrodemecanismo paraadquirirresistencia es la alteración en la permeabilidad de los antibióticos debido a la pérdida de porinas, principalmente debido a mutaciones, lo que provocaría un aumento en la concentración mínima inhibitoria de los antibióticos, requiriendo dosis cada vez más altas. Esta alteración suele darse principalmente en el caso de bacterias gramnegativas, ya que su pared externa presenta este tipo de estructuras. Adicionalmente se puede sospechar que la pérdida de porinas podría relacionarse con alteraciones a nivel genético, relacionados con el gen bla $a_{\mathrm{KPC}}$ que provoca una alteración de la permeabilidad de manera frecuente en la resistencia frente a los carbapenems, como por ejemplo imipenem o meropenem, situación que también se demuestra en esta investigación $(38,39)$.

En Colombia, en un estudio realizado en cuidados intensivos en 10 hospitales se comprobó que la $A$. baumannii presentaron altos porcentajes de resistencia a diferentes antibióticos entre los cuales se encontraban los carbapenems. Dicha resistencia se relacionó directamente con la presencia de las enzimas carbapenemasas OXA-23 y OXA-151, cuyos genes fueron localizados en el cromosoma o en plásmidos $(15,26)$.

De igual manera, otro de los mecanismos conocidos que podrían generar resistencia a antibióticos y que se suele dar principalmente en el caso de gramnegativas como la $A$. baumannii es la presencia de bombas de salida o de expulsión, cuya función es provocar la expulsión de los antibióticos, pudiendo darse el caso de que la molécula sea reconocida previamente antes de ser expulsada, las cuales suelen relacionarse con la resistencia a las quinolonas como la ciprofloxacina. Es probable que este mecanismo de resistencia sea adquirido mediante transferencia horizontal de genes. Los artículos que fueron revisados en esta investigación demuestran la resistencia de la ciprofloxacina, pudiendo tratarse de este mecanismo de resistencia $(40,41)$.

Los diferentes mecanismos que la $A$. baumannii puede generar, evidencian el grave problema al momento de tratar infecciones nosocomiales multirresistentes. Según el SENTRY (Antimicrobial Surveillance Program), en Latinoamérica, la $A$. baumannii presenta las tasas más altas de resistencia bacteriana. Dichos reportes mencionan a Estados Unidos como uno de los países que presentan altas tasas de resistencia a antibióticos, alcanzando alrededor del $90 \%$ de resistencia a ciprofloxacino, y al menos $80 \%$ frente a cefalosporinas de amplio espectro, en cambio, casi el $49 \%$ presenta resistencia a ampicilina/ sulbactam $(13,42)$.

Con base en la información recopilada, mediante la revisión y análisis de los diferentes artículos se evidenció el aumento de la resistencia de la $A$. baumannii; convirtiéndose en la principal causante de infecciones nosocomiales a nivel hospitalario, principalmente en los pacientes que se encuentran inmunodeprimidas $u$ 
hospitalizadas en las áreas de cuidados intensivos, ya que dentro de esta área se encuentran pacientes que son sometidos a procesos invasivos, siendo esta una de las más rápidas vías de proliferación y la causa de infecciones producidas por esta $(43,44)$.

Por consiguiente, los porcentajes de resistencia que la $A$. baumannii ha generado a los tratamientos con antimicrobianos ha variado en las últimas décadas, provocando un aumento con los años. Dentro de los principales grupos de antibióticos de uso común a los cuales se observa una acelerada resistencia se pueden destacar aminoglucósidos como la gentamicina, tobramicina y amikacina, carbapenems, como meropenem e imipenem. Las cefalosporinas también se incluyen en este grupo, entre ellas se mencionan cefepime y ceftazidima. Entre las quinolonas que se emplearon en las investigaciones demostraron resistencia a ciprofloxacina y levofloxacino $(16,19,23,25)$.

La investigación también demostró la capacidad de la bacteria de generar resistencia a los $\beta$-lactámicos como la piperacilina/ tazobactam, ampicilina, ticarcillina / ácido clavulánico y otros como el trimetropin/ sulfametoxazol $(27,29,30)$.

Finalmente, lo fundamental para lograr un mejor control en las infecciones generadas por la A. baumannii, es identificar de manera oportuna la presencia de este microorganismo en las diferentes áreas de atención médica, su resistencia a antibióticos y aplicar medidas de corrección adecuadas como procedimientos de desinfección en cada área utilizando desinfectantes que permitan una reducción de la carga bacteriana en superficies inertes para prevenir una transmisión directa e indirecta (45).

Se debe recalcar la importancia que tienen los procedimientos de asepsia al paciente o en las manos del personal sanitario, procesos importantes en la cadena de transmisión de una infección, así como realizar seguimiento y control en los tratamientos con antibióticos específicos a través del análisis con antibiogramas para conocer la sensibilidad y utilizar terapias específicas y eficaces que eviten la generación de nuevos mecanismos de resistencia $(46,47)$.

\section{CONCLUSIÓN}

La $A$. baumanni ha llegado a causar preocupación por su alta capacidad de resistencia y supervivencia provocando complicaciones al elegir las terapias adecuadas y prolongar la estancia de los pacientes en el área hospitalaria.

La $A$. baumannii se convirtió en una bacteria oportunista que con el transcurso de tiempo ganó gran importancia dentro del área hospitalaria, convirtiéndose en uno de los principales microorganismos causantes de un gran número de infecciones nosocomiales, aumentando así la tasa de mortalidad en pacientes inmunodeprimidos hospitalizados en el área de $\mathrm{UCl}$.

La investigación permite concluir que los tratamientos tradicionales óptimos para una infección causada por la A. baumannii se 
alteraron o provocaron un aumento en sus concentraciones, por lo tanto, en la actualidad un adecuado tratamiento se consigue con la selección del antibiótico ideal mediante un antibiograma previo, el cual permite verificar la susceptibilidad y la resistencia del microorganismo a los diferentes antibióticos, dosis empleada y farmacocinética del medicamento.

Para ejercer un mejor control en la prevencióndelasinfeccionesintrahospitalarias, es de suma importancia el uso de indicadores válidos en función de las metas, objetivos y prioridades de los programas, que puedan ser utilizados por las instituciones de salud con el propósito de llevar un control de la calidad del servicio continuo, así como en la toma de decisiones por el programa nacional en los diferentes niveles de organización del sistema de salud.

\section{REFERENCIAS BIBLIOGRÁFICA}

1. Copana Olmos RR, Guzman Rivera G. Factores de riesgo asociados a infecciones por Acinetobacter baumannii en una unidad de cuidados intensivos pediátricos. Gac Médica Boliv. junio de 2016;39(1):06-9.

2. Salazar-Holguín HD, Cisneros-Robledo ME. Resistencia a los antimicrobianos de agentes causales de las principales infecciones nosocomiales. Rev Med Inst Mex Seguro Soc. :11.

3. Díaz-Vélez C, Neciosup-Puicán E, FernándezMogollón JL, Tresierra-Ayala MÁ, ApolayaSegura M. Mortalidad atribuible a infecciones nosocomiales en un hospital de la Seguridad Social en Chiclayo, Perú. Acta Médica Peru. julio de 2016;33(3):250-2.
4. López Méndez L, Pastrana Román I, González Hernández JC, Álvarez Reinoso S, Rodríguez Ramos JF. Caracterización de las infecciones nosocomiales. Rev Cienc Médicas Pinar Río. abril de 2013;17(2):86-97.

5. Maguiña Vargas C. Infecciones nosocomiales. Acta Médica Peru. julio de 2016;33(3):175-7.

6. Olaechea PM, Insausti J, Blanco A, Luque P. Epidemiología e impacto de las infecciones nosocomiales. Med Intensiva. mayo de 2010;34(4):256-67.

7. Fariñas MC, Martínez-Martínez L. Infecciones causadas por bacterias gramnegativas multirresistentes: enterobacterias, Pseudomonas aeruginosa, Acinetobacter baumannii y otros bacilos gramnegativos no fermentadores. Enfermedades Infecc Microbiol Clínica. 1 de junio de 2013;31(6):402-9.

8. Ruíz-González KJ, Pacheco-Pérez LA, Paz-Morales M de los Á, Ruíz-González KJ, Pacheco-Pérez LA, Paz-Morales $M$ de los Á. Gestión del cuidado de enfermería en infección por Acinetobacter Baumannii: caso clínico. Sanus [Internet]. marzo de 2020 [citado 19 de mayo de 2021];5(13). Disponible en: http:// www.scielo.org.mx/scielo.php?script $=$ sci_ abstract\&pid=S2448-60942020000100004\&lng =es\&nrm=iso\&tlng=es

9. Hernández-Gómez C, Blanco VM, Motoa G, Correa A, Maya JJ, De la Cadena E, et al. Evolución de la resistencia antimicrobiana de bacilos Gram negativos en unidades de cuidados intensivos en Colombia. Biomédica. 5 de noviembre de 2013;34(0):91.

10. Influence of Genospecies of Acinetobacter baumannii Complex on Clinical Outcomes of Patients with Acinetobacter Bacteremia | Clinical Infectious Diseases | Oxford Academic [Internet]. [citado 9 de mayo de 2021]. Disponible en: https://academic.oup.com/cid/ article/52/3/352/307420 
11. Antunes L, Visca P, Towner K. Acinetobacter baumannii: Evolution of a global pathogen. Pathog Dis. 24 de diciembre de 2013;71.

12. Casellas JM. Resistencia a los antibacterianos en América Latina: consecuencias para la infectología. Rev Panam Salud Pública. diciembre de 2011;30:519-28.

13. Londoño Restrepo J, Macias Ospina IC, Ochoa Jaramillo FL. Factores de riesgo asociados a infecciones por bacterias multirresistentes derivadas de la atención en salud en una institución hospitalaria de la ciudad de Medellín 2011-2014. Infectio. abril de 2016;20(2):77-83.

14. García Apac C. Resistencia antibiótica en el Perú y América Latina. Acta Médica Peru. abril de 2012;29(2):99-103.

15. Cuaical Ramos NM, Delgado Borrero YA, Anzola Anzola YM, Marcano Zamora D, Torres LC. Detección de carbapenemasas tipo OXA en aislados de Acinetobacter baumannii de diferentes centros hospitalarios de Caracas, Venezuela. Rev Soc Venez Microbiol. diciembre de 2012;32(2):95-110.

16. Hart Casares $M$, Espinosa Rivera F, Halley Posada M del C, Martínez Batista ML, Montes de Oca Méndez Z. Resistencia a antibióticos en cepas de Acinetobacter baumannii aisladas de enero a marzo del 2010 en el Hospital Clinicoquirúrgico «Hermanos Ameijeiras». Rev Cuba Med. septiembre de 2010;49(3):218-27.

17. Troncoso C, Pavez M, Santos A, Salazar R, Barrientos L, Troncoso $C$, et al. Implicancias Estructurales y Fisiológicas de la Célula Bacteriana en los Mecanismos de Resistencia Antibiótica. Int J Morphol. diciembre de 2017;35(4):1214-23.

18. Ramos PM, Velilla SM. Resistencia a aminoglucósidos por los genes aph(3')-Vla y aac(3')-II en Acinetobacter baumannii aislados en Montería, Colombia. :10.
19. Vanegas-Múnera JM, Roncancio-Villamil $G$, Jiménez-Quiceno JN. Acinetobacter baumannii: importancia clínica, mecanismos de resistencia y diagnóstico. 2014;(2):14.

20. Barletta Farías $R$, Pérez Ponce $L$, Castro Vega G, Pujol Pérez $M$, Barletta del Castillo J, Dueñas Pérez Y. Acinetobacter baumannii multirresistente: un reto para la terapéutica actual. MediSur. abril de 2018;16(2):322-34.

21. Pérez Morales L, Barletta Castillo J, Quintana Hernández $\mathrm{H}$, Reyes Rodríguez I, Otero Espino N. Estudio clínico, epidemiológico y microbiológico de pacientes con neumonía asociada a la ventilación mecánica ingresados en salas de cuidados intensivos. MediSur. agosto de 2012;10(4):268-78.

22. Amo D, Alier M, García-Peñalvo F, Fonseca D, Casañ MJ. Privacidad, seguridad y legalidad en soluciones educativas basadas en Blockchain: Una Revisión Sistemática de la Literatura. RIED Rev Iberoam Educ Distancia. 1 de julio de 2020;23(2):213-36.

23. Prado $A$, Arias NL, Chávez $M$, Cabrera $C E$, Gómez RF. Caracterización fenotípica de aislamientos de Acinetobacter baumannii en una institución de salud de alta complejidad de Cali. Biomédica. 13 de noviembre de 2013;34(0):101.

24. Vanegas JM, Higuita LF, Vargas C, Vargas $C$, CienfuegosAV,RodríguezE, et al.Acinetobacter baumannii resistente a carbapenémicos causando osteomielitis e infecciones en piel y tejidos blandos en hospitales de Medellín, Colombia. Biomédica [Internet]. 28 de mayo de 2015 [citado 10 de mayo de 2021];35(4). Disponible en: http://www.revistabiomedica. org/index.php/biomedica/article/view/2572

25. Higgins PG, Dammhayn C, Hackel M, Seifert H. Global spread of carbapenem-resistant Acinetobacter baumannii. J Antimicrob Chemother. febrero de 2010;65(2):233-8. 
26. Patrones de resistencia a antibióticos de Acinetobacter baumannii en un hospital de Colombia [Internet]. [citado 10 de mayo de 2021]. Disponible en: http:// www.scielo.org.pe/scielo.php?script $=$ sci arttext\&pid=S1025-55832015000200004

27. Rincón-León HA, Navarro-Fuentes KR. Tendencias de resistencia antimicrobiana en patógenos aislados de infecciones nosocomiales. Rev Med Inst Mex Seguro Soc. $: 11$.

28. Zeighami $H$, Valadkhani $F$, Shapouri $R$, Samadi E, Haghi F. Virulence characteristics of multidrug resistant biofilm forming Acinetobacter baumannii isolated from intensive care unit patients. BMC Infect Dis. 17 de julio de 2019;19(1):629.

29. Qi L, Li H, Zhang C, Liang B, Li J, Wang L, et al. Relationship between Antibiotic Resistance, Biofilm Formation, and Biofilm-Specific Resistance in Acinetobacter baumannii. Front Microbiol [Internet]. 2016 [citado 12 de mayo de 2021];7. Disponible en: https://www.frontiersin. org/articles/10.3389/fmicb.2016.00483/full

30. Deylam Salehi M, Ferdosi-Shahandashti E, Yahyapour Y, Khafri S, Pournajaf A, Rajabnia R. Integron-Mediated Antibiotic Resistance in Acinetobacter baumannii Isolated from Intensive Care Unit Patients, Babol, North of Iran. BioMed Res Int. 19 de julio de 2017;2017:e7157923.

31. Pujol M, Limón E. Epidemiología general de las infecciones nosocomiales. Sistemas y programas de vigilancia. Enfermedades Infecc Microbiol Clínica. 1 de febrero de 2013;31(2):108-13.

32. Zúñiga-Bahamon $A$, Tobar $F$, Duque JF, Moreno P.Acinetobacter baumannii: Resistance and Virulence mediated through bacterial type IV secretion system. Rev Estomatol. 29 de septiembre de 2017;21(2):37-45.
33. Rojas GC, Ulate LA. RESISTENCIA ANTIMICROBIANA: MICROORGANISMOS MÁS RESISTENTES Y ANTIBIÓTICOS CON MENOR ACTIVIDAD. :7.

34. Lee $C-R$, Lee $J H$, Park $M$, Park KS, Bae IK, Kim YB, et al. Biology of Acinetobacter baumannii: Pathogenesis, Antibiotic Resistance Mechanisms, and Prospective Treatment Options. Front Cell Infect Microbiol. 2017;7:55.

35. Zaragoza R, Ramírez P, López-Pueyo MJ. Infección nosocomial en las unidades de cuidados intensivos. Enfermedades Infecc Microbiol Clínica. 1 de mayo de 2014;32(5):3207.

36. Hart Casares M, Espinosa Rivera F, Halley Posada M del C, Martínez Batista ML, Montes de Oca Méndez Z. Resistencia a antibióticos en cepas de Acinetobacter baumannii aisladas de enero a marzo del 2010 en el Hospital Clinicoquirúrgico «Hermanos Ameijeiras». Rev Cuba Med. septiembre de 2010;49(3):218-27.

37. Morejón García M. Betalactamasas de espectro extendido. Rev Cuba Med. diciembre de 2013;52(4):272-80.

38. Navarro F, Calvo J, Cantón R, FernándezCuenca F, Mirelis B. Detección fenotípica de mecanismos de resistencia en microorganismos gramnegativos. Enfermedades Infecc Microbiol Clínica. 1 de agosto de 2011;29(7):524-34.

39. Pacheco R, Osorio L, Correa AM, Villegas MV. Prevalencia de bacterias Gram negativas portadoras del gen blaKPC en hospitales de Colombia. Biomédica. 22 de octubre de 2013;34(0):81.

40. Álvarez-Hernández DA, Garza-Mayén GS, Vázquez-López R. Quinolonas: Perspectivas actuales y mecanismos de resistencia. Rev Chil Infectol. octubre de 2015;32(5):499-504. 
41. Carbapenémicos: Tipos y mecanismos de resistencia bacterianos [Internet]. [citado 23 de mayo de 2021]. Disponible en: https:// www.medigraphic.com/cgi-bin/new/resumen. cgi?IDARTICULO=47783

42. Rodriguez Buenahora RD, Bustillo Zarate DE, Caicedo Sanchez DC, Cadena Sarmiento DC, CastellanosGomezC.Acinetobacterbaumannii: patógeno multirresistente emergente. Medicas UIS. agosto de 2016;29(2):113-35.

43. Carcassés LMG, Hernández LP, Enseñat YP, Loyola CNP. Caracterización de pacientes con neumonía por Acinetobacter baumannii asociada a la ventilación mecánica en las Unidades de Cuidados Progresivos Characterization of Patients with Acinetobacter baumannii Ventilator-associated Pneumonia in Progressive Care Units. 2016;16.

44. AL-Kadmy IMS, Ali ANM, Salman IMA, Khazaal SS. Molecular characterization of Acinetobacter baumannii isolated from Iraqi hospital environment. New Microbes New Infect. 1 de enero de 2018;21:51-7.

45. Rodriguez Buenahora RD, Bustillo Zarate DE, Caicedo Sanchez DC, Cadena Sarmiento DC, CastellanosGomezC.Acinetobacterbaumannii: patógeno multirresistente emergente. Medicas UIS. agosto de 2016;29(2):113-35.

46. Hernández RN. Lectura interpretada del antibiograma. Rev Cuba Med Mil. diciembre de 2013;42(4):502-6.

47. Velázquez Brizuela IE, Aranda Gama J, Camacho Cortes JL, Ortíz GG. Epidemiología de infecciones nosocomiales en el Instituto Jalisciense de Cancerología. Rev Cuba Salud Pública. marzo de 2013;39(1):19-31.

Conflicto de intereses: Ninguno declarado por los autores. Financiación: Ninguna declarada por los autores.

Agradecimiento: Ninguno manifestado por los autores

\section{ACERCA DE LOS AUTORES}

Rosa Carolina Encalada Álvarez. Química Farmaceuta. Magister en Diagnostico de Laboratorio Clínico y Molecular, Universidad Católica de Cuenca. Jefa de Laboratorio y Farmacia, Hospital Universitario Católico Cuenca. Universidad Católica de Cuenca, Ecuador.

Sandra Denisse Arteaga Sarmiento. Doctora en Bioquímica y Farmacia. Magíster en Seguridad Salud y Ambiente. Técnico en Seguridad, Universidad Católica de Cuenca. Docente en la carrera de Bioquímica y Farmacia en la Universidad Católica de Cuenca, Ecuador. 